\title{
Entropy of Mixing of Liquid NaCd System
}

\author{
S.K. Chatterjee ${ }^{1}$, L.C. Prasad ${ }^{2}$ and A. Bhattarai ${ }^{3}$ \\ ${ }^{1,3}$ Department of Chemistry, Mahendra Morang Adrash Multiple Campus, Biratnagar, \\ Tribhuvan University, Nepal \\ ${ }^{2} P$ G Department of Chemistry, T M Bhagalpur University, Bhagalpur 812 007, Bihar,India \\ email: sujeetkumarchatterjee@yahoo.com
}

\begin{abstract}
The observed asymmetric behaviour of mixing properties of $\mathrm{NaCd}$ liquid alloys, with smaller negative value for excess free energy of mixing $(-4.4919 \mathrm{KJ})$ has aroused our interest to undertake a theoretical investigation of this system. The existence of an intermetallic compound in the solid phase, which is manifested in the phase diagram, may be one of the factors for the anomalous behaviour of property of mixing. A simple statistical mechanical theory based on complex formation model (the complex is formed by the preferential arrangement of A and $\mathrm{B}$ constituent

atoms of the alloy $\mathrm{AB} ;\left(\mu \mathrm{A}+v \mathrm{~B} \rightleftharpoons \mathrm{A}_{\mu} \mathrm{B}_{v}\right)$ has been used to investigate the phenomena of compound formation in $\mathrm{NaCd}$ liquid alloys through the study of entropy of mixing through out the whole concentration range.
\end{abstract}

Key Words: Free energy of mixing $\left(\mathrm{G}_{M}\right)$,Heat of mixing $\left(\mathrm{H}_{\mathrm{M}}\right)$,Entropy of mixing $\left(\mathrm{S}_{\mathrm{M}}\right)$, concentration fluctuation in the long wave length region $\left[\mathrm{S}_{\mathrm{cc}}(\mathrm{o})\right]$ and chemical short range order parameter $\left(\alpha_{1}\right)$

\section{Introduction}

Theoreticians have worked with various models (Young 1992, Singh \& March 1995, Singh 1987, Sommer 1990, Bhatia \& Singh 1984, Prasad \& Singh 2000, Singh \& Sommer 1992, Hoshino 1983, Ruppersberg \& Reiter 1982 and Prasad et al. 2007) to understand the alloying behaviour of compound forming alloys. All the theoretical models led to the fact that interatomic interaction plays an important role in compound formation.

Due to the presence of strong interatomic interaction these alloys in the solid, form intermetallic compounds at one or more stoichiometric composition, which is also manifested in the phase diagram (Hultgreen et al. 1973) of such alloys. The formation of compound in the solid state, led many theoreticians to believe in the existence of chemical complexes, pseudomolecules a privileged group of atoms near the melting temperature in binary molten alloy.

The mixing behaviour of such alloy is generally understood (Komarek 1983, Sommer 1988) through the concentration dependent thermodynamic and microscopic properties such as $G_{M}, H_{M}, S_{M}$, $\left[S_{c c}(o)\right]$ and $\alpha_{1}$. These properties are nearly affected due to compound formation.
Here in the present work statistical mechanicaltheory based on compound formation, have been used to investigate the asymmetry in the property of mixing, which might be caused due to the existence of $\mathrm{Cd}_{2} \mathrm{Na}$ complex in the melt.

The expression of entropy mixing obtained by using the theoretical model are in section 1 , while section 2 deals with numerical result and discussion, conclusion is provided in section 3 .

\section{Theory}

Let the binary alloy $\mathrm{AB}$ consists of $\mathrm{N}_{\mathrm{A}}(=(\mathrm{NC})$ number of atoms $\mathrm{A}$, and $\mathrm{N}_{\mathrm{B}}(=\mathrm{N}(1-\mathrm{C})$ number of $\mathrm{B}$ atoms, so that the total number of atoms $\mathrm{N}$ becomes equal to $\mathrm{N}_{\mathrm{A}}+\mathrm{N}_{\mathrm{B}}$ .Following (Bhatia \& Hargrove 1974) it is assumed that chemical complexes $\mathrm{A}_{\mu} \mathrm{B}_{v}\left(\mu \mathrm{A}+v \mathrm{~B} \rightleftharpoons \mathrm{A}_{\mu} \mathrm{B}_{v}\right)$ exist in the melt $\mu$ and $\nu$ are integers which are usually determined from the compound forming concentration $\left(C_{c}=\frac{\mu}{\mu+v}\right)$ in the solid state. Because of the existence of the compound, liquid alloys are assumed to be composed of three species; free $A$ atom, $B$ atom and chemical complex $A_{\mu} B_{v}$ i.e. ternary 
Nepal Journal of Science and Technology 10(2009)105-108

mixture the number of free atoms will be reduced due to the compound formation in the melt. If $n_{1}, n_{2}$ and $n_{3}$ are the number of $\mathrm{A}$ atom, $\mathrm{B}$ atom and the compound $\mathrm{A}_{\mu} \mathrm{B}_{v}$, respectively, then from conservation of atoms we have,

$\mathrm{n}_{1}=\mathrm{NC}-\mu \mathrm{n}_{3}$

$\mathrm{n}_{2}=\mathrm{N}(1-\mathrm{C})-v \mathrm{n}_{3}$

$\mathrm{n}=\mathrm{n}_{1}+\mathrm{n}_{2}+\mathrm{n}_{3}=\mathrm{N}-(\mu+v-1) \mathrm{n}_{3}$

where $\mathrm{n}$ is the total number of atoms in the case of compound formation. Under the frame work of above model the free energy of mixing, $\mathrm{G}_{\mathrm{M}}$ can be expressed as

$\mathrm{G}_{\mathrm{M}}=-\mathrm{n}_{3} \mathrm{~g}+\mathrm{G}_{1}$

Where $-n_{3}$ g represents the lowering of free energy due to complex formation energy of complex. $G_{1}$ is the free energy of mixing of the ternary mixture of fixed $n_{1}, n_{2}$ and $\mathrm{n}_{3}$, whose constituents $\mathrm{A}, \mathrm{B}$ and $\mathrm{A}_{\mu} \mathrm{B}_{v}$ are assumed to interact weakly with one another.

A simple approximate expression for $G_{1}$ taking into account of the difference in the size between the unassociated species and complex is that due to (Flory 1942) given as

$G_{1}=R T\left[\sum_{i=1}^{2} n_{i} \ln \left(n_{i} / N\right)+n_{3} \ln \left[(\mu+v) n_{3} / N\right]\right]+$

$R T\left[\sum \sum_{i<j}\left\{\left(n_{i} n_{j} / N\right) V_{i j} / R T\right\}\right]$

Where $V_{i j}(i, j=1,2,3)$ are the interaction energies through which the left over $\mathrm{A}$ atom, $\mathrm{B}$ atom and the complex $\mathrm{A}_{\mu} \mathrm{B}_{v}$ interact with one another. The energies $\mathrm{V}_{\mathrm{ij}}$ are independent of concentration but may depend upon temperature and pressure. It is convenient to write the expression for $\mathrm{G}_{\mathrm{M}}$ from Eqs. (2) and (3):

$$
\begin{aligned}
& G_{M}=-n_{3} g+R T\left[\sum_{i=1}^{2} n_{i} \ln \left(n_{i} / N\right)+n_{3} \ln \left[(\mu+v) n_{3} / N\right]\right]+ \\
& R T\left[\sum \sum_{i<j}\left\{\left(n_{i} n_{j} / N\right) V_{i j} / R T\right\}\right]
\end{aligned}
$$

The main problem in the evaluation of $\mathrm{G}_{\mathrm{M}}$ as a function of concentration the equilibrium relation, given below, is considered:

$\left(\frac{\partial G_{M}}{\partial n_{3}}\right)=0$

Eqs.(4) and (5) give

$n_{1}^{\mu} n_{2}^{v}=n_{3} N^{\mu+v-1}(\mu+v) \exp [-(\mu+v-1)-g / R T+Z]$
Where $\mathrm{Z}=(\mathrm{NRT})-1\left[\left(n_{1}-\mu n_{3}\right) V_{13}+\left(n_{2}-v n_{3}\right) V_{23}\right.$
$\left.-\left(\mu n_{2}+v n_{1}\right) V_{12}\right]$

Once the expression for $\mathrm{G}_{\mathrm{M}}$ obtained, other thermodynamic and microscopic functions follow readily. Heat of mixing and entropy of mixing are related to $G_{M}$ through standard thermodynamic relations:

$H_{M}=G_{M}-T\left(\frac{\partial G_{M}}{\partial T}\right)_{T, P, N}$

$\mathrm{S}_{\mathrm{M}}=\left(\mathrm{H}_{\mathrm{M}}-\mathrm{G}_{\mathrm{M}}\right) / \mathrm{T}$

When eq. (4) is used in eqs. (8), we obtain expression for $\mathrm{H}_{\mathrm{M}}$

$H_{M}=-n_{3} g+n_{3} T\left(\frac{\partial G}{\partial T}\right)_{P}+\sum \sum_{i<j}\left(n_{i} n_{j} / N\right)\left[V_{i j}-T\left(\frac{\partial V_{i j}}{\partial T}\right)_{P}\right]_{(9)}$

\section{Results and Discussion}

The lower value of excess free energy of mixing $\mathrm{G}_{\mathrm{M}}{ }^{\mathrm{XS}}$ ($4.49 \mathrm{KJ})$ at compound forming concentration $\left(C_{c}=\frac{\mu}{\mu+v}\right) C_{c d}=0.66$ indicates the tendency of compound formation is weak. The value of $\mu$ and $v$ which are usually selected from the compositional dependence of the physical properties and atom from the phase diagram are taken for $\mathrm{NaCd}$ system as $\mu=2$ and $\nu=1$ respectively.

The method suggested by (Bhatia \& Hargrove 1974) was applied to obtain the starting value of $g$ and $V_{\mathrm{ij}}$. For $\mathrm{NaCd}$ system the value of $\mathrm{g}$ as equal to $-(\mu+v) G_{M}$ i.e. $\left(-3 G_{M}\right)$ for our computation.

The value of $g$ and $V_{i j}$ were adjusted through computer simulations to yield the concentration dependence of $G_{M}$ via eqs(4) and (6). The above process repeated until a good fit for $G_{M}$ or $G_{M}$ Xs is obtained. The interaction energy $\left(\mathrm{V}_{\mathrm{ij}}\right)$ and the temperature derivative $\left(\frac{\partial V_{i j}}{\partial T}\right)$ have been fixed for the system as

$\left(\frac{g}{R T}=1.5, \frac{V_{12}}{R T}=3.0, \frac{V_{13}}{R T}=0.9, \frac{V_{23}}{R T}=1.7\right)$

$\frac{\partial g}{R T}=-6.0, \frac{\partial V_{12}}{R T}=0, \frac{\partial V_{13}}{R T}=-0.55, \frac{\partial V_{23}}{R T}=-5.0$

\section{Entropy of mixing}

The computed values of $\mathrm{S}_{\mathrm{M}}$ along with the experimental values (Hultgreen et al. 1973) are tabulated in table 1. The $\mathrm{S}_{\mathrm{M}}$ vs $\mathrm{C}_{\mathrm{cd}}$ curve show good agreement 
between theoretical and experimental values except at $\mathrm{C}_{\mathrm{Cd}}=0.9$. This may be due to the influence of the ideal part $\left\lfloor S_{M}=S_{M}^{X S}-S_{M}^{i d}\right\rfloor$

The theoretical values of $\mathrm{S}_{\mathrm{M}}$ are positive at all concentration where as the experimental values are found negative around $\mathrm{C}_{\mathrm{Cd}}=0.9$. The existence of atomic order may be inferred for the positive values of $\mathrm{S}_{\mathrm{M}}$ at all concentration except $\mathrm{C}_{\mathrm{Cd}}=0.9$.

It is also clear from equation (11) that the interaction between left over $\mathrm{Na}$ and $\mathrm{Cd}$ atoms $\left(\mathrm{V}_{12}\right)$ is independent of temperature.

Table 1. Entropy of mixing for $\mathrm{NaCd}$ liquid alloys at $673 \mathrm{~K}$

\begin{tabular}{|l|l|l|}
\hline $\mathrm{C}_{\mathrm{Cd}}$ & Theory & Expt. $^{*}$ \\
\hline 0.1 & 0.233 & 0.244 \\
\hline 0.2 & 0.335 & 0.366 \\
\hline 0.3 & 0.364 & 0.359 \\
\hline 0.4 & 0.332 & 0.321 \\
\hline 0.5 & 0.253 & 0.239 \\
\hline 0.6 & 0.139 & 0.143 \\
\hline 0.7 & 0.031 & 0.053 \\
\hline 0.8 & 0.010 & -0.010 \\
\hline 0.9 & 0.097 & -0.023 \\
\hline
\end{tabular}

* Hultgren et al 1973

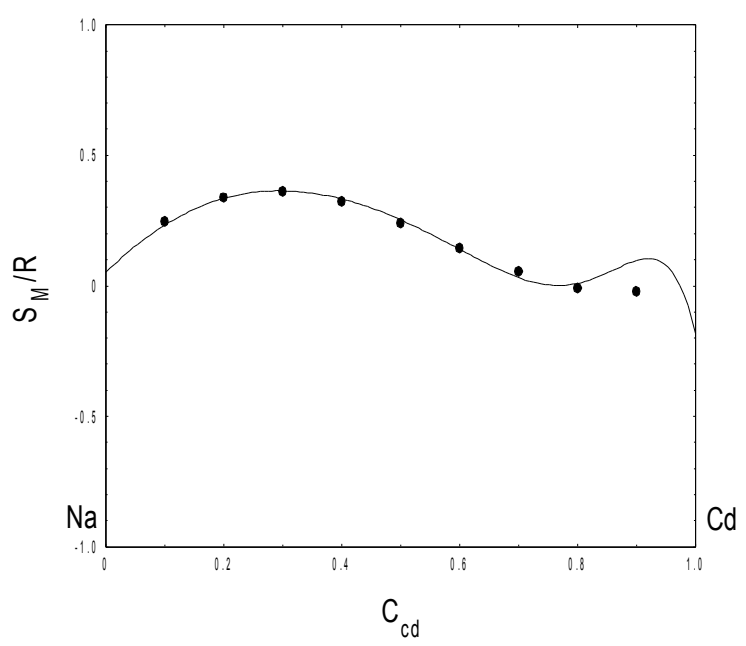

Fig.1. $\mathrm{S}_{\mathrm{M}} / \mathrm{R}$ vs $\mathrm{C}_{\mathrm{cd}}$ for $\mathrm{NaCd}$ liquid alloys at $673 \mathrm{~K}$ (solid lines): theory ;( closed circles): experiment (Hultgren et al 1973).
Our theoretical model which assumes the existence of $\mathrm{Cd}_{2} \mathrm{Na}$ complex in $\mathrm{NaCd}$ liquid alloys, explain successfully the concentration dependent asymmetry in the entropy of mixing.

The computed values of $S_{M} / R$ are positive at all concentration, showing the atomic order. There are reasonable agreement between theory and experiment in the concentration range $0.1<\mathrm{Ccd}<0.8$, beyond this range a distinct deviation in magnitude of $\mathrm{S}_{\mathrm{M}} / \mathrm{R}$ is observed, for $\mathrm{NaCd}$ liquid alloy.

\section{Acknowledgement}

The authors are greatful to Prof. R. N. Singh, presently at the department of Physics, Sultan Quaboos University, Muscat, OMAN for his valuable suggestions and discussions.

\section{References}

Bhatia, A. B. and R. N. Singh. 1984. A Quasi-lattice theory compound forming molten alloys. Physics and Chemistry of Liquids: An International Journal 13: $177-190$.

Bhatia, A. B. and W. H. Hargrove. 1974. Concentration fluctuations and thermodynamic properties of some compound forming binary molten systems. Physical Review B 10: 3186-3196.

Flory,P.J. 1942.Thermodynamics of high polymer solutions. The Journal of Chemical Physics 10: 51-61.

Hoshino, K. 1983. On the temperature dependence of the structure factor of the liquid Li-Pb alloy. Journal of Physics F: Metal Physics 13: 189-191.

Hultgreen, R., P. D. Desai, D .T. Hawkins, M.Gleiser, K. K. Kelly and D. D. Wagman. 1973. Selected values of the thermodynamic properties of the Binary alloys. American Society for metals, Metal park, Ohio.

Komarek, K. L. 1983. Recent Developments in the experimental determination of thermodynamic quantities of metals and alloys. Ber. Bunsenges. Phys. Chem 87: 709-717.

Prasad, L. C. and V. N. Singh. 2000. Surface properties and concentration fluctuations in Sn-based molten alloys.Z. Naturforsch 55a : 967-972.

Prasad, L. C., S.K. Chatterjee and R.K. Jha. 2007. Atomic order and interionic pair potentials in $\mathrm{Cu}-\mathrm{Sn}$ liquid alloys. Journal of Alloys and Compounds 441: 43-51.

Ruppersberg, H. and H. Reiter. 1982. Chemical short-range order in liquid LiPb alloys. Journal of Physics F: Metal Physics 12: 1311-1325.

Singh, R.N.and N.H.March.1995.Intermetallic compounds, Vol.1. ( Eds J.H. Wertbrook and R.L. Fleischer).Wiley, New york 661pp. 
Nepal Journal of Science and Technology 10(2009) 105-108

Singh,R. N. 1987. Short-range order and concentration fluctuations in binary molten alloys. Canadain Journal of Physics 65: 309-325.

Singh,RNandF.Sommer.1992.Temperature dependence of the thermodynamic functions of strongly interacting liquid alloys. Journal of Physics: Condensed Matter 4: 5345-5358.

Sommer, F. 1990.Thermodynamic properties of compound-forming liquid alloys. Journal of Non-Crystalline Solids 117: 505-512.
Sommer, F. J. 1988. Modern methods in high temperature calorimetry. Journal of Thermal Analysis and Calorimetry 33: 15-28.

Young, W. H. 1992. Structural and thermodynamic Properties of NFE liquid metals and binary alloys. Reports on Progress in Physics 55: 1769-1853. 